\title{
HEAVY METAL POLLUTION OF SURFACE SEDIMENTS IN THE NORTHERN WATERS OF THE ABANDONED YELLOW RIVER DELTA IN JIANGSU PROVINCE OF CHINA AND ECOLOGICAL RISK ASSESSMENT
}

\author{
WANG, J. ${ }^{1}-$ ZHANG, Y. M..$^{2 *}$ XU, M. ${ }^{1}-$ LIU, B. Q. ${ }^{1}$ \\ ${ }^{1}$ College of Marine Science and Engineering, Nanjing Normal University, Nanjing 210023, \\ China \\ ${ }^{2}$ School of Environment, Nanjing Normal University, Nanjing 210023, China \\ *Corresponding author \\ e-mail:09352@njnu.edu.cn \\ (Received $18^{\text {th }}$ Jun 2019; accepted $16^{\text {th }}$ Oct 2019)
}

\begin{abstract}
We studied the distribution, pollution characteristics, and ecological risk of heavy metal pollutants in the northern waters of the abandoned Yellow River Delta in Jiangsu Province of China in the surface sediments in May 2018. The results show that the average content of $\mathrm{As}, \mathrm{Cu}, \mathrm{Pb}, \mathrm{Zn}$, and $\mathrm{Cd}$, exceeds their respective background concentration in the tidal marshes of Jiangsu. Analysis of the pollution load index shows that the pollution level is rated as medium pollution; analysis of the composite potential ecological risk index indicates that the level is medium-high, and the waters from the Zhongshan River estuary to the Abandoned Yellow River estuary have the highest level of heavy metal pollution and are most susceptible to ecological risk. Heavy metal content increases from the Guan River estuary to the Abandoned Yellow River estuary, as well as from the shore to the sea with the estuaries and near-shore port areas having the highest content of heavy metals. The content of $\mathrm{Cr}$ is mainly derived from natural sources, while other heavy metals primarily originate from the pollutants discharged into the sea from rivers, marine outfalls and marine development activities like port construction and wind-power development.
\end{abstract}

Keywords: pollution characteristics, potential ecological risk, spatial distribution, correlation analysis, clustering analysis

\section{Introduction}

As sensitive regions that connect the continent with the sea, estuaries and coasts are areas where both life and production thrive and where pollutants and sediments from rivers accumulate (Li et al., 2007; Wang et al., 2008; Reddy et al., 2016). Heavy metals are toxic, durable, bio-accumulative, contributive to ecological risks, and hard to decompose (Nguyen et al., 2016; Harikrishnan et al., 2017; Jahan and Strezov, 2018; Zhao et al., 2018). Therefore, heavy metal pollution is receiving considerable attention from researchers because it threatens marine ecology and human health (Phillips et al., 2016; Keshavarzi et al., 2018; Wang et al., 2018). Due to the rapid economic development along coastlines in recent years, marine heavy metal pollution has exacerbated, and human activities are primarily responsible for the majority of this pollution in estuaries and coastal areas throughout the world (Begy et al., 2016; Guan et al., 2016; Monferran et al., 2016). Marine sediments act as a repository of heavy metals in the sea. Moreover, because of the absorption and sedimentation of suspended matters, most heavy metals in the sea get deposited in marine sediments; however, when the environment changes, these heavy metals are released into the sea again and cause pollution (Singh et al., 2005; Guan et al., 2016). Compared to sea water and marine 
organisms, marine sediments usually contain more heavy metals and can provide more accurate detection results (Liang et al., 2018); therefore, the concentration of heavy metals in sediments is an important environmental indicator.

Located in the central and northern coastal areas of Jiangsu province in China (Fig. 1), the abandoned Yellow River Delta has an erosion coast and the $-15 \mathrm{~m}$ isobath and $-10 \mathrm{~m}$ isobath on top of the delta are $3.95 \mathrm{~km}$ and $2.0 \mathrm{~km}$ away from the coastal baseline, respectively, which indicates that the water is deep along the coast. Therefore, this area offers ideal conditions for building a large port. The rivers joining the sea in the study area include the Guan River, Zhongshan River and the abandoned Yellow River, with average discharge of $475 \mathrm{~m}^{3} / \mathrm{s}, 175 \mathrm{~m}^{3} / \mathrm{s}$ and $103 \mathrm{~m}^{3} / \mathrm{s}$ respectively. Furthermore, because of the rich resources from the adjacent continent and the strategy of developing coastal areas of Jiangsu province, the development of the northern waters of the Abandoned Yellow River Delta is gaining pace. The primary activities in the area are port development, waste discharge, aquaculture, and wind power development. The Guan River Port is located at the estuary of Guan River, whereas another port is under construction along the coastline from the abandoned Yellow River to Erhongkou. Within the eastern seawall of the Zhongshan River estuary, an industrial park is being developed (occupied primarily by chemical plants). The industrial waste water from this park is discharged into the sea via outfalls that are $6 \mathrm{~km}$ away from the Zhongshan River estuary with the daily volume of discharge reaching 20,000 tons. Toward the south of the industrial park is an aquaculture area, and the wastewater from this area is discharged into the sea through gated channels. Furthermore, there are three marine wind-power stations in the study area (A, B and C in Fig. 1).

As the coastal economy takes off, the development activities along the coastline will increase, which will lead to additional environmental problems in the delta. Note that the concentration of heavy metals in marine sediments can reflect the level of pollution in the sea. Previous studies on heavy metal concentration in coastal sediments in Jiangsu, such as studies on pollution characteristics, sources, and ecological risks of heavy metals in surface sediments in Haizhou Bay and the radiating shoals, have focused on certain regions. There have been no studies on the sources and ecological risks of heavy metals in sediments of the northern waters of the Abandoned Yellow River delta. In this study, we focused on this region as the study area and used the sediment statistics of 2018 to analyze the concentration of heavy metals in surface sediments in this area. The aims of this study are as follows: i) to analyze the concentration and distribution characteristics of seven heavy metals in surface sediments in the northern waters of the Abandoned Yellow River Delta; ii) to assess the pollution level and ecological risks of seven heavy metals in surface sediments in the study area; and iii), to identify the possible sources of heavy metal pollution in the study area via correlation and clustering analyses. The results revealed heavy metal pollution in the surface sediments of the northern waters of the Abandoned Yellow River Delta, and the effect of human activities on the sediment environment, which would provide a scientific basis for environmental protection and pollution treatment in the study area.

\section{Materials and methods}

\section{Study area description}

Located in the central and northern waters of Jiangsu province in China, the study area extends from the Zhongshan River estuary to the abandoned Yellow River estuary 
and extends $50 \mathrm{~km}$ outward into the sea (Fig. 1). The study area belongs to the northern waters of the Abandoned Yellow River Delta. With the headland on the north of the Abandoned Yellow River estuary as the point of inflexion, the coastline meanders from northwest to southeast, and then runs from north to south. The coast is a plain erosion silt-muddy coast.

The substrate of the Abandoned Yellow River Delta primarily comprises clayey silt, silt, and sandy silt with a median grain size of $6-8 \mu \mathrm{m}$. Clayey silt accounts for $80 \%$ of the total fine particles in the study area, whereas silt accounts for 10\%-20\%; therefore, the study area is the best in Jiangsu in terms of the concentration of fine particles $(\mathrm{Hu}$, 2014). The grain size of sediments in the Abandoned Yellow River Delta decreases from west to east with the major type of sediments changing from sandy silt to clayey silt (Chen, 2014; Hu, 2014). Guan River, which is to the north of the Abandoned Yellow River, is the largest river that joins the sea in Jiangsu, and because of the sediments it carries to the estuary, the grain size of particles in the estuary is relatively big (Hu, 2014; Zhang, 2016). The distribution of sediments is consistent with the change in water depth and landform. From the Guan River estuary to the Zhongshan River estuary, the major particles are sandy silt; however, from the Zhongshan River estuary to the port, the major particles are silt and clayey silt (Hu, 2014).

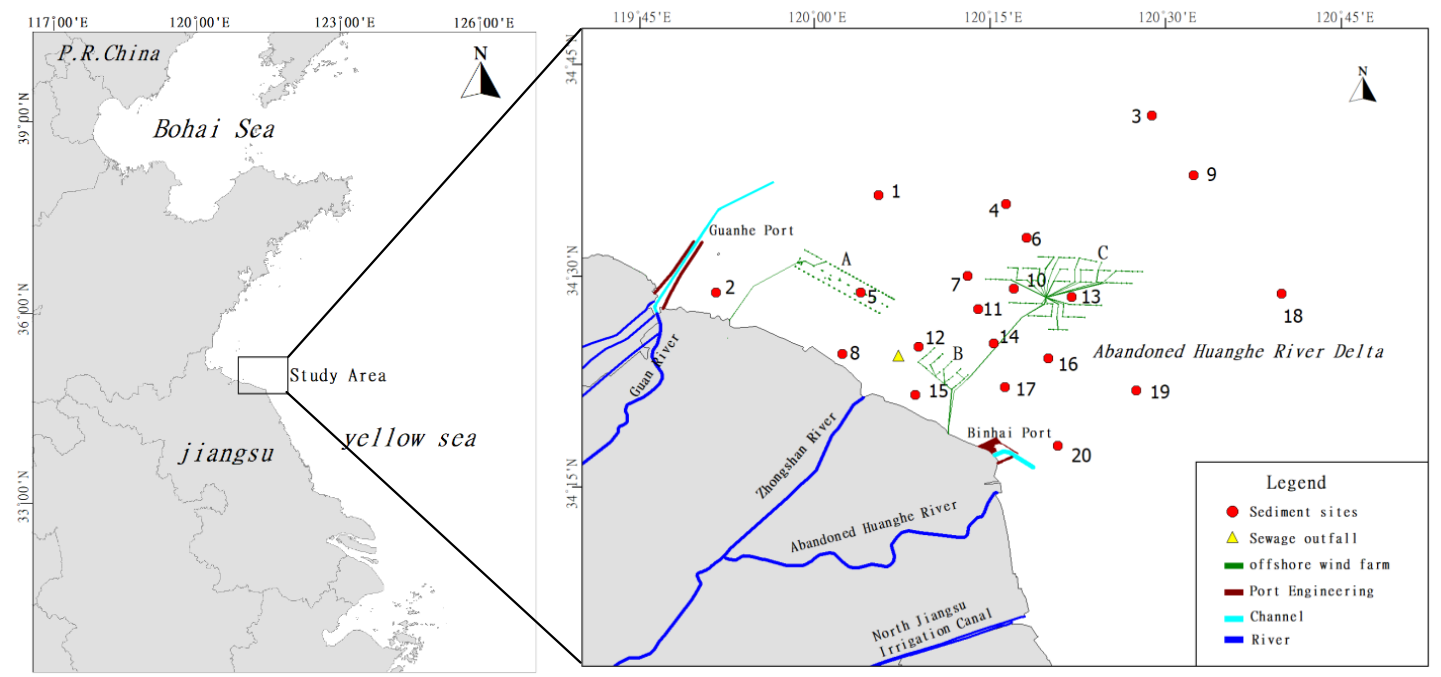

Figure 1. Location of sample sites

\section{Sampling and sample processing}

We conducted the on-site sampling in May 2018. A total of 20 surface-sediment samples were collected from the sampling sites (Fig. 1). The sampling point coordinate range is $34^{\circ} 18^{\prime} 56.34^{\prime \prime} \mathrm{N}-34^{\circ} 42^{\prime} 32.61^{\prime \prime} \mathrm{N}, 119^{\circ} 52^{\prime} 11.18^{\prime \prime} \mathrm{E}-120^{\circ} 40^{\prime} 20.99^{\prime \prime} \mathrm{E}$. The test subjects were seven heavy metals, i.e., $\mathrm{Hg}, \mathrm{As}, \mathrm{Cu}, \mathrm{Pb}, \mathrm{Zn}, \mathrm{Cd}$, and $\mathrm{Cr}$. We conducted the sampling was according to technical regulations established by "Specifications of Marine Monitoring (GB17378-2007)" and "Specifications for Oceanographic Survey (GB/T 12763-2007)". To remove the overlying water, the sediment samples were collected through a grab sampler on the deck. In particular, to test for $\mathrm{Cu}, \mathrm{Zn}, \mathrm{Pb}$, and $\mathrm{Cd}$, we obtained 500-600 g of wet sample and added it into a clean polyethylene bag, and then sealed the bag. Similarly, to test for petroleum pollutants, organic carbon, and 
total mercury, we obtained 500-600 g of wet sample and added it to a $500 \mathrm{ml}$ widemouth bottle, which was then sealed. All wide-mouth bottles were filled with nitrogen, placed in shady areas, and frozen at a low temperature. The frozen samples were winddried, and then placed in shady but well-ventilated indoor sites. From these samples, we removed gravels and large debri-like particles (obtained from plants and animals) before they were placed into the agate mortar where these samples were grinded till they were able to pass through a 160-mesh sieve. The mixture was then used for further characterization of chemical elements. We analyzed the test results according to "Specifications of Marine Monitoring - Part 5: Sediment Analysis (GB17378.5-2007)". The atomic fluorescence method was used in order to determine the As and $\mathrm{Hg}$ concentrations by AFS-930 Atomic Fluorescence Spectrometer. Flameless atomic absorption spectrophotometry method was used to determine the $\mathrm{Cu}, \mathrm{Pb}$ and $\mathrm{Cr}$ concentration and flame atomic absorption spectrophotometry method was used to determine the $\mathrm{Zn}$ and Cd levels and all by VARIAN AA240FS Atomic Absorption Spectrophotometer.

\section{Methods}

\section{Pollution load index (PLI)}

The pollution load index was first proposed by Tomlinson in 1980 to assess pollution by different chemical elements at different sites. The equations for calculation are:

$$
\begin{gathered}
C_{f}^{i}=C_{\mathrm{n}}^{i} / C_{0}^{i} \\
P L I=\sqrt[n]{C_{f}^{1} \times C_{f}^{2} \times C_{f}^{3} \times \ldots \times C_{f}^{\mathrm{n}}}
\end{gathered}
$$

where PLI refers to the pollution load index of a certain site, $C_{f}^{i}$ the pollution index of one element, $C_{\mathrm{n}}^{i}$ the value obtained through actual measurement, and $C_{0}^{i}$ the background value. The grading standard for PLI (Tomlinson et al., 1980; Zhu et al., 2013) is shown in Table 1.

\section{Geo-accumulation index}

Geo-accumulation Index (Igeo) was first proposed by G. Müller, a German scientist. It is a quantitative index for assessment of heavy metal contents in sediments and can be used to assess pollution caused by heavy metal contents. The calculation equation is:

$$
I_{\text {geo }}=\log _{2} \frac{C_{n}}{1.5 B_{n}}
$$

where $\mathrm{Cn}$ denotes the content of Element $\mathrm{n}$ in actual measurement, and $\mathrm{Bn}$ is the background value of this element on earth which, in this research, specifically refers to the background value of the content of the researched element in the tidal marsh of Jiangsu province measured in the 1980 s by Chen et al. (1985). 1.5 is a coefficient identified by considering possible changes caused by differences of rocks in different places. The grading standard of geo-accumulation index (Müller, 1969) is also shown in Table 1 . 


\section{Potential ecological risk index}

The potential ecological risk index was first proposed by a Swedish environmentalist named Hakanson in 1980 to assess the potential ecological hazards of heavy metal contents in sediments. This method combines the ecological impact, environmental impact and toxicologic research of heavy metal contents to reflect the potential ecological risks of heavy metals. The calculation equations are:

$$
\begin{gathered}
E_{r}^{i}=T_{r}^{t} \times C_{f}^{i} \\
R I=\sum\left(E_{\mathrm{r}}^{i}\right)
\end{gathered}
$$

where $R I$ is the value of comprehensive potential ecological risks, $E_{r}^{i}$ the value of potential risks of one element. $T_{r}^{t}$ denotes the toxicological coefficient of an element which, in this research, adopts the standard toxicological coefficients of heavy metal contents proposed by Hakanson (1980): the respective toxicological coefficients of $\mathrm{Cd}$, $\mathrm{As}, \mathrm{Cu}, \mathrm{Pb}, \mathrm{Cr}$ and $\mathrm{Zn}$ are $30,10,5,5,2$, and $1 . C_{f}^{i}$ is the pollution coefficient of a certain element, $C_{n}{ }^{i}$ the value obtained through actual measurement and $C_{0}{ }^{i}$ the background value. The grading standard for the potential ecological risk index of a given element and for the comprehensive potential ecological risk index is also presented in Table 1.

Table 1. Grading standard for geo-accumulation index and potential ecological risk index of

\begin{tabular}{|c|c|c|c|c|c|c|c|}
\hline $\begin{array}{c}\text { Geo- } \\
\text { accumulation } \\
\text { index }\left(I_{g e o}\right) \text { value }\end{array}$ & $\begin{array}{c}\text { Pollution } \\
\text { level }\end{array}$ & $\begin{array}{l}\text { Pollution } \\
\text { load index } \\
(P L I) \text { value }\end{array}$ & $\begin{array}{c}\text { Pollution } \\
\text { level }\end{array}$ & \begin{tabular}{|c|} 
Single-factor \\
potential \\
ecological \\
risk $\left(E_{r}{ }^{i}\right)$ \\
\end{tabular} & $\begin{array}{c}\text { Single-factor } \\
\text { potential } \\
\text { ecological } \\
\text { risk level } \\
\end{array}$ & $\begin{array}{c}\text { Comprehensive } \\
\text { potential } \\
\text { ecological risk } \\
\text { value }(R I) \\
\end{array}$ & $\begin{array}{c}\text { Comprehensive } \\
\text { potential } \\
\text { ecological risk } \\
\text { level } \\
\end{array}$ \\
\hline$\leq 0$ & $\begin{array}{c}\text { No } \\
\text { pollution }\end{array}$ & $<1$ & No pollution & $<40$ & Low & $<110$ & Low \\
\hline $0 \sim 1$ & $\begin{array}{c}\text { Mild } \\
\text { pollution }\end{array}$ & $1 \sim 2$ & $\begin{array}{l}\text { Medium } \\
\text { pollution }\end{array}$ & $40 \sim 80$ & Medium & $110 \sim 220$ & Medium \\
\hline $1 \sim 2$ & $\begin{array}{l}\text { Mild- } \\
\text { medium } \\
\text { pollution }\end{array}$ & $2 \sim 3$ & $\begin{array}{c}\text { Heavy } \\
\text { pollution }\end{array}$ & $80 \sim 160$ & Medium-high & $220 \sim 440$ & High \\
\hline $2 \sim 3$ & $\begin{array}{l}\text { Medium } \\
\text { pollution }\end{array}$ & $\geq 3$ & $\begin{array}{c}\text { Severe } \\
\text { pollution }\end{array}$ & $160 \sim 320$ & High & $\geq 440$ & Extremely high \\
\hline $3 \sim 4$ & $\begin{array}{l}\text { Serious } \\
\text { pollution }\end{array}$ & & & $\geq 320$ & $\begin{array}{c}\text { Extremely } \\
\text { high }\end{array}$ & & \\
\hline $4 \sim 5$ & $\begin{array}{c}\text { Heavy } \\
\text { pollution }\end{array}$ & & & & & & \\
\hline$>5$ & $\begin{array}{c}\text { Severe } \\
\text { pollution }\end{array}$ & & & & & & \\
\hline
\end{tabular}
heavy metal contents

\section{Statistical and mapping methods}

We performed Pearson correlation coefficients between each pair of heavy metals and clustering analysis for the seven heavy metals obtained data from 20 sampling sites by using SPSS. Combining with the spatial information of station location, the data are processed by using Suffer11 software and Kristin interpolation method, and the spatial 
distribution maps of heavy metal contents in surface sediments, pollution load index, and the comprehensive ecological risk index.

\section{Result and discussion}

\section{Heavy metal concentration and distribution}

Table 2 shows the concentration of different heavy metals in the surface sediments of the study area in May 2018. The concentration range of heavy metals $(\mathrm{mg} / \mathrm{kg})$ in the surface sediments of the study area are as follows. The concentration of $\mathrm{Hg}$ was $0.0064-0.0287 \mathrm{mg} / \mathrm{kg}$ (average of $0.0177 \mathrm{mg} / \mathrm{kg}$ ); that of As was $5.72-18.1 \mathrm{mg} / \mathrm{kg}$ (average of $12.635 \mathrm{mg} / \mathrm{kg}$ ); that of $\mathrm{Cu}$ was $17.9-27.7 \mathrm{mg} / \mathrm{kg}$ (average of $22.28 \mathrm{mg} / \mathrm{kg}$ ); that of $\mathrm{Pb}$ was $17.4-25.8 \mathrm{mg} / \mathrm{kg}$ (average of $21.77 \mathrm{mg} / \mathrm{kg}$ ); that of $\mathrm{Zn}$ was $60.4-$ $80.2 \mathrm{mg} / \mathrm{kg}$ (average of $70.89 \mathrm{mg} / \mathrm{kg}$ ); that of Cd was $0.137-0.264 \mathrm{mg} / \mathrm{kg}$ (average of $0.18 \mathrm{mg} / \mathrm{kg}$ ); and that of Cr was $35.8-56.7 \mathrm{mg} / \mathrm{kg}$ (average of $40.86 \mathrm{mg} / \mathrm{kg}$ ).

In comparison with the heavy metal contents in sediments obtained by studies in other areas of China (Table 2), the average content of $\mathrm{Hg}, \mathrm{As}, \mathrm{Cu}, \mathrm{Pb}, \mathrm{Zn}, \mathrm{Cd}, \mathrm{Cr}$ in sediments in the study area stayed at a medium level.

Table 2. Heavy metal contents of surface sediments in the study area and comparison with other areas $(\mathrm{mg} / \mathrm{kg})$

\begin{tabular}{|c|c|c|c|c|c|c|c|c|c|}
\hline & & $\begin{array}{c}\text { Mercury } \\
(\mathbf{H g})\end{array}$ & $\begin{array}{c}\text { Arsenic } \\
\text { (As) }\end{array}$ & $\begin{array}{c}\text { Copper } \\
(\mathrm{Cu})\end{array}$ & $\begin{array}{l}\text { Lead } \\
(\mathrm{Pb})\end{array}$ & $\begin{array}{l}\text { Zinc } \\
(\text { Zn) }\end{array}$ & $\begin{array}{c}\text { Cadmium } \\
\text { (Cd) }\end{array}$ & $\begin{array}{c}\text { Chromium } \\
\text { (Cr) }\end{array}$ & Source \\
\hline \multirow{3}{*}{$\begin{array}{c}\text { Contents } \\
\text { in the } \\
\text { study area }\end{array}$} & Maximum & 0.0287 & 18.1 & \begin{tabular}{|l|}
27.7 \\
\end{tabular} & 25.8 & 80.2 & 0.264 & 56.7 & \multirow{3}{*}{ This study } \\
\hline & Minimum & 0.0064 & 5.72 & 17.9 & 17.4 & 60.4 & 0.137 & 35.8 & \\
\hline & Mean & 0.0177 & 12.635 & 22.28 & 21.77 & 70.89 & 0.18 & 40.86 & \\
\hline \multicolumn{2}{|c|}{$\begin{array}{c}\text { First category standard } \\
\text { of "Marine Sediment } \\
\text { Quality Standard (GB } \\
18668-2002) "\end{array}$} & 0.20 & 20.0 & 35.0 & 60.0 & 150.0 & 0.50 & 80.0 & $\begin{array}{l}\text { Marine Sediment } \\
\text { Quality Standard } \\
\text { (GB 18668-2002) }\end{array}$ \\
\hline \multicolumn{2}{|c|}{$\begin{array}{l}\text { Soil background value } \\
\text { of tidal marsh in } \\
\text { Jiangsu province }\end{array}$} & 0.023 & 7.38 & 15.02 & 11.40 & 47.15 & 0.042 & 60.11 & Chen et al. (1985) \\
\hline \multicolumn{2}{|c|}{$\begin{array}{l}\text { Eastern China } \\
\text { intertidal zone }\end{array}$} & 0.03 & 8.11 & 18.9 & 23.05 & 69.61 & 0.09 & 70.03 & Zhang et al.(2017) \\
\hline \multicolumn{2}{|c|}{ Jiangsu coastal areas } & 0.023 & 14.8 & 18.3 & 20.7 & 53.0 & 0.113 & 64.0 & Zheng et al.2017 \\
\hline \multicolumn{2}{|c|}{$\begin{array}{l}\text { Guangdong coastal } \\
\text { region }\end{array}$} & 0.13 & 20.83 & 43.83 & 44.29 & 139.93 & 0.38 & 86.97 & Zhao et al.(2016) \\
\hline \multicolumn{2}{|c|}{ Laizhou Bay, China } & n.d. & 4.84 & 6.89 & 14.01 & n.d. & 0.08 & 17.10 & $\begin{array}{l}\text { Zhang et al. } \\
\text { (2017) }\end{array}$ \\
\hline \multicolumn{2}{|c|}{ Bohai Bay } & n.d. & n.d. & 38.5 & 44 & 206.3 & 0.22 & 101.4 & Wu et al. (2014) \\
\hline \multicolumn{2}{|c|}{ Sheyang Estuary } & 0.02 & 12.84 & 23.51 & 16.87 & 62.16 & 0.15 & 37.19 & Zhao et al. (2018) \\
\hline \multicolumn{2}{|c|}{ Haizhou Bay } & n.d. & 6.62 & 19.41 & 18.23 & 73.29 & 0.17 & 74.18 & LI et al. (2014) \\
\hline \multicolumn{2}{|c|}{ Ganyu port } & n.d. & 11.6 & 25.6 & 16 & 56 & 0.08 & 40 & LI et al. (2014) \\
\hline \multicolumn{2}{|c|}{ Dafeng port } & n.d. & 12.1 & 10.3 & 14.7 & 48.7 & 0.1 & 74.5 & LI et al. (2014) \\
\hline
\end{tabular}

Note: n.d. means not detected

In 2018, the average contents of seven heavy metal in sediment did not go beyond the first category standard of "Marine Sediment Quality Standard (GB 18668-2002)". The average concentration of five heavy metals, i.e., $\mathrm{As}, \mathrm{Cu}, \mathrm{Pb}, \mathrm{Zn}$, and $\mathrm{Cd}$, exceeded the background concentration in the tidal marshes in Jiangsu, and the ratios of their 
average concentration to the background concentration were $1.71,1.48,1.91,1.50$, and 4.29 (Table 3), respectively. Among the abovementioned metals, $\mathrm{Cd}$ has the highest single-factor pollution index.

Figure 2 shows the distribution of heavy metal in the northern waters of abandoned Yellow River delta. The concentration of $\mathrm{Cr}$ is below the background value, which indicates that the presence of this metal is less subject to human activities and its natural level can be maintained. Related studies show that $\mathrm{Cr}$ is primarily derived from nature and is subject to properties of the soil form in the parental material, making it a heavy metal of low pollution ( $\mathrm{Lv}$ et al., 2013; Sun et al., 2013). The concentration of $\mathrm{Cr}$ increases from the Guan River estuary to the abandoned Yellow River estuary, and then from the shore towards the sea. The distribution of heavy metal concentration is consistent with the changes in the grain size of sediments. In the study area, the grain size of sediments reduces from the Guan River estuary to the abandoned Yellow River estuary, and then from the shore to the sea (Chen, 2014; Hu, 2014). Many studies have reported that the concentration of heavy metals is closely correlated to the grain size of sediments (Li et al., 2015): if the surface area of the particle sediments is large, more heavy metals will be absorbed, while if the grain size of the particles is large, the concentration of heavy metals will be lesser. Generally, the concentration of the other heavy metals increased from the Guan River estuary to the abandoned Yellow River estuary, and then from the shore to the sea with the estuary and the port area showing the highest values of concentration.

\section{Heavy metal pollution characteristics}

Table 4 shows the pollution load indices (Eqs. 1 and 2) of heavy metals in sediments in the study area. Figure 3 shows the distribution of pollution load indices of each sampling site. Note that the pollution load indices in these sampling sites ranged from 1.04 to 1.61 (average of 1.47); hence, according the grading standard for Pollution Load Index shown in Table 1, the study area was identified to have medium pollution. However, the pollution load index increased from the Guan River estuary to the abandoned Yellow River estuary with waters from the Zhongshan River estuary to the Abandoned Yellow River estuary showing the largest indices.

Table 5 shows the geo-accumulation index $(E q .3)$ of heavy metals in the surface sediments in the study area. The $I_{g e o}$ for the tested heavy metals are as follows: -2.42 to -0.27 for $\mathrm{Hg}$ (average of -1.03 ); -0.95 to 0.71 for As (average of 0.10 ); -0.33 to 0.30 for $\mathrm{Cu}$ (average of -0.02 ); $0.03-0.59$ for $\mathrm{Pb}$ (average of 0.34 ); -0.23 to 0.18 for $\mathrm{Zn}$ (average of 0.00 ); $1.12-2.07$ for $\mathrm{Cd}$ (average of 1.50 ); and -1.33 to -0.67 for $\mathrm{Cr}$ (average of -1.15 ). In terms of $I_{g e o}$, the seven heavy metals are ranked as follows: $\mathrm{Cd}>\mathrm{Pb}>\mathrm{As}>\mathrm{Zn}>\mathrm{Cu}>\mathrm{Hg}>\mathrm{Cr}$. According the grading standard of geoaccumulation index shown in Table $1, \mathrm{Cd}$ is marked at the level from mild-medium pollution to medium pollution; $\mathrm{Pb}$ is marked as mild pollution; $\mathrm{As}, \mathrm{Cu}$, and $\mathrm{Zn}$ are marked as clean- mild pollution; and $\mathrm{Hg}$ and $\mathrm{Cr}$ are marked as clean.

Table 3. Single-factor pollution index of heavy metal in surface sediments

\begin{tabular}{c|c|c|c|c|c|c|c}
\hline & $\begin{array}{c}\text { Mercury } \\
(\mathbf{H g})\end{array}$ & $\begin{array}{c}\text { Arsenic } \\
(\mathbf{A s})\end{array}$ & $\begin{array}{c}\text { Copper } \\
(\mathbf{C u})\end{array}$ & $\begin{array}{c}\text { Lead } \\
(\mathbf{P b})\end{array}$ & $\begin{array}{c}\text { Zinc } \\
(\mathbf{Z n})\end{array}$ & $\begin{array}{c}\text { Cadmium } \\
(\mathbf{C d})\end{array}$ & $\begin{array}{c}\text { Chromium } \\
(\mathbf{C r})\end{array}$ \\
\hline Maximum & 1.25 & 2.45 & 1.84 & 2.26 & 1.70 & 6.29 & 0.94 \\
Minimum & 0.28 & 0.78 & 1.19 & 1.53 & 1.28 & 3.26 & 0.60 \\
Mean & 0.77 & 1.71 & 1.48 & 1.91 & 1.50 & 4.29 & 0.68 \\
\hline
\end{tabular}


Wang et al.: Heavy metal pollution of surface sediments in northern waters of the abandoned Yellow River Delta in Jiangsu Province of China and ecological risk assessment

$$
-14874 \text { - }
$$

Table 4. Pollution load index (PLI) and pollution level of heavy metals in surface sediments of the study area

\begin{tabular}{c|c|c|c}
\hline Sampling site & $\begin{array}{c}\text { Pollution load index (PLI) } \\
\text { value }\end{array}$ & Sampling site & $\begin{array}{c}\text { Pollution load index (PLI) } \\
\text { value }\end{array}$ \\
\hline 1 & 1.54 & 11 & 1.55 \\
2 & 1.04 & 12 & 1.58 \\
3 & 1.21 & 13 & 1.55 \\
4 & 1.54 & 14 & 1.51 \\
5 & 1.25 & 15 & 1.57 \\
6 & 1.46 & 16 & 1.53 \\
7 & 1.58 & 17 & 1.61 \\
8 & 1.36 & 18 & 1.61 \\
9 & 1.25 & 19 & 1.57 \\
10 & 1.50 & 20 & 1.57 \\
\hline Maximum & 1.61 & Minimum & 1.04 \\
Mean & 1.47 & Pollution level & Medium pollution \\
\hline
\end{tabular}

Table 5. Geo-accumulation index and potential ecological risk index of heavy metals in surface sediments of the study area

\begin{tabular}{|c|c|c|c|c|c|c|c|c|}
\hline & & $\begin{array}{c}\text { Mercury } \\
(\mathbf{H g})\end{array}$ & $\begin{array}{c}\text { Arsenic } \\
\text { (As) }\end{array}$ & $\begin{array}{c}\text { Copper } \\
(\mathbf{C u})\end{array}$ & $\begin{array}{c}\text { Lead } \\
(\mathbf{P b})\end{array}$ & $\begin{array}{l}\text { Zinc } \\
(\mathrm{Zn})\end{array}$ & $\begin{array}{l}\text { Cadmium } \\
(\mathrm{Cd})\end{array}$ & $\begin{array}{c}\text { Chromium } \\
(\mathrm{Cr})\end{array}$ \\
\hline \multirow{4}{*}{$\begin{array}{l}\text { Geo-accumulation } \\
\text { index }\left(I_{g e o}\right)\end{array}$} & Maximum & -0.27 & 0.71 & 0.30 & 0.59 & 0.18 & 2.07 & -0.67 \\
\hline & Minimum & -2.42 & -0.95 & -0.33 & 0.03 & -0.23 & 1.12 & -1.33 \\
\hline & Mean & -1.03 & 0.10 & -0.02 & 0.34 & 0.00 & 1.50 & -1.15 \\
\hline & $\begin{array}{l}\text { Degree of } \\
\text { pollution }\end{array}$ & Clean & $\begin{array}{l}\text { Clean-mild } \\
\text { pollution }\end{array}$ & $\begin{array}{l}\text { Clean-mild } \\
\text { pollution }\end{array}$ & $\begin{array}{l}\text { Mild } \\
\text { pollution }\end{array}$ & $\begin{array}{l}\text { Clean- } \\
\text { mild } \\
\text { pollution }\end{array}$ & \begin{tabular}{|c|} 
Mild-medium \\
pollution - \\
medium pollution
\end{tabular} & Clean \\
\hline \multirow{4}{*}{$\begin{array}{l}\text { Single-factor } \\
\text { potential } \\
\text { ecological risk } \\
\qquad\left(E_{r}^{i}\right)\end{array}$} & Maximum & 49.91 & 24.53 & 9.22 & 11.32 & 1.70 & 188.57 & 1.89 \\
\hline & Minimum & 11.18 & 7.75 & 5.96 & 7.63 & 1.28 & 97.86 & 1.19 \\
\hline & Mean & 30.80 & 17.12 & 7.42 & 9.55 & 1.50 & 128.82 & 1.36 \\
\hline & Ecological risk & $\begin{array}{l}\text { Low - } \\
\text { medium }\end{array}$ & Low & Low & Low & Low & $\begin{array}{l}\text { Medium-high - } \\
\text { high }\end{array}$ & Low \\
\hline \multirow{4}{*}{$\begin{array}{l}\text { Comprehensive } \\
\text { potential } \\
\text { ecological risk } \\
(R I)\end{array}$} & Maximum & \multicolumn{7}{|c|}{247.33} \\
\hline & Minimum & \multicolumn{7}{|c|}{146.68} \\
\hline & Mean & \multicolumn{7}{|c|}{196.57} \\
\hline & Ecological risk & \multicolumn{7}{|c|}{ Medium - High } \\
\hline
\end{tabular}
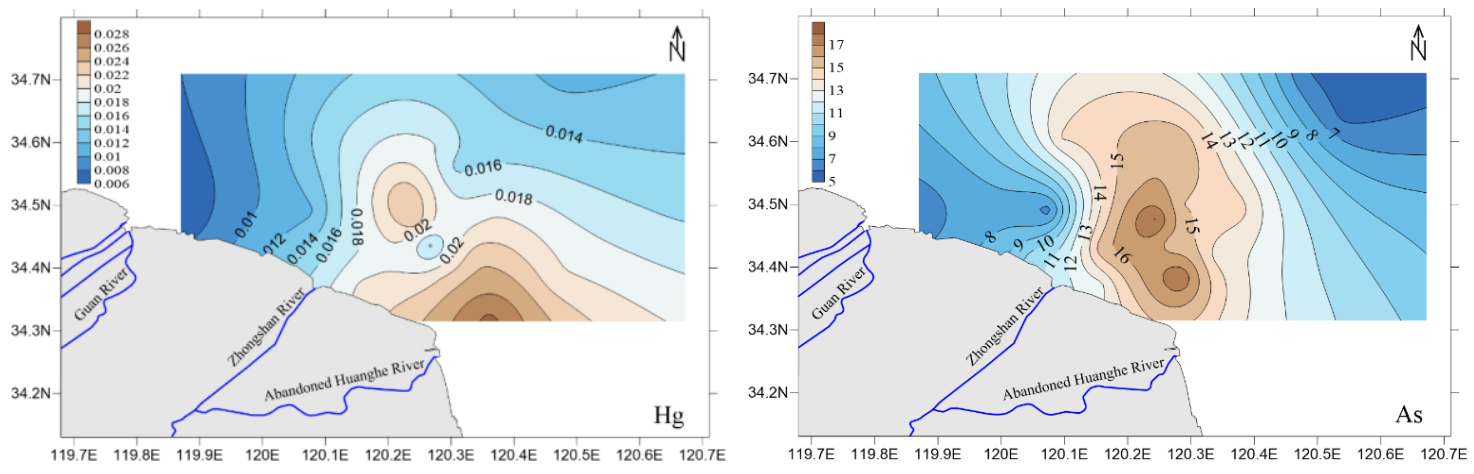

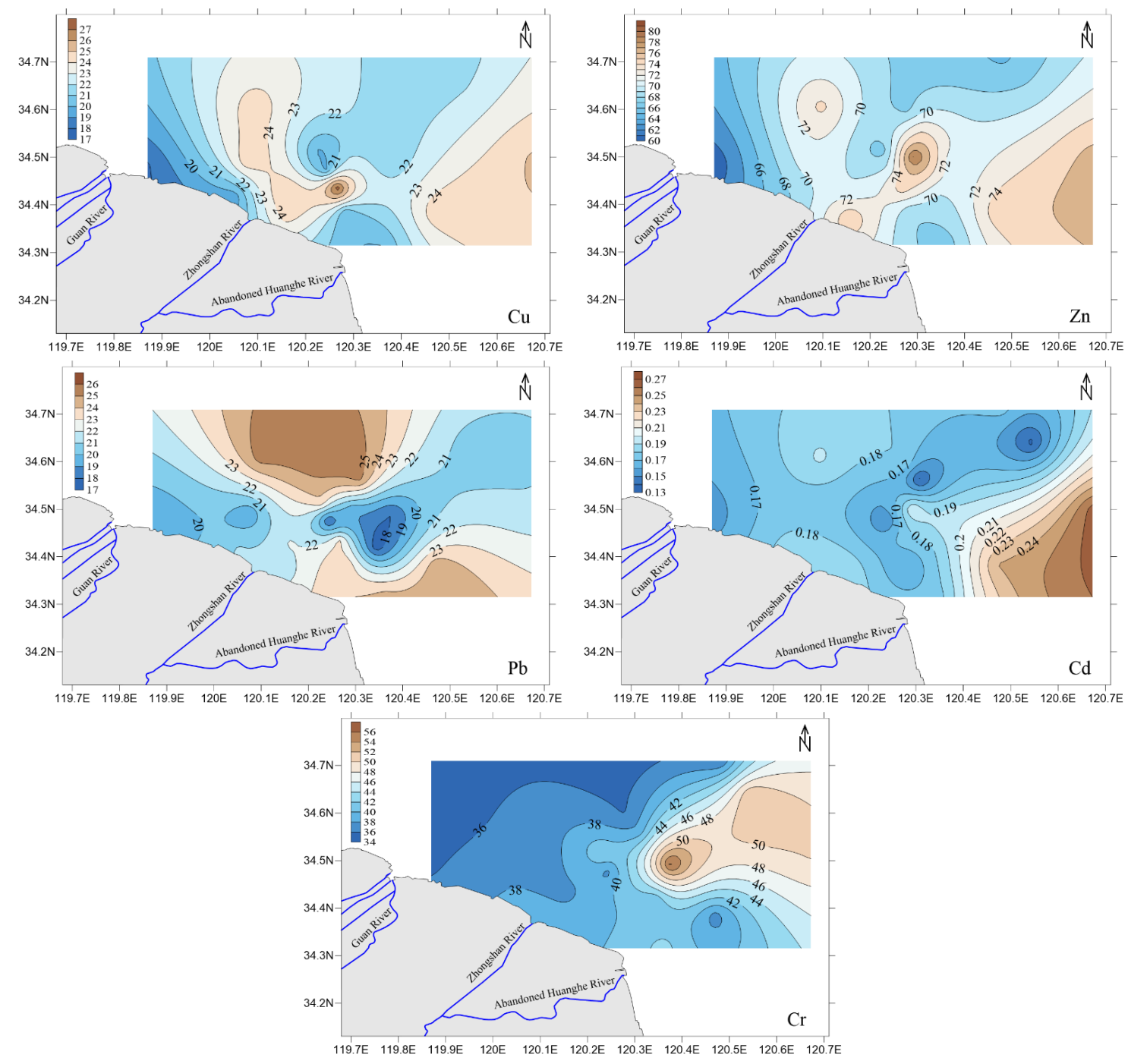

Figure 2. Spatial distribution of heavy metal contents in 2018 (unit: $\mathrm{mg} / \mathrm{kg}$ )

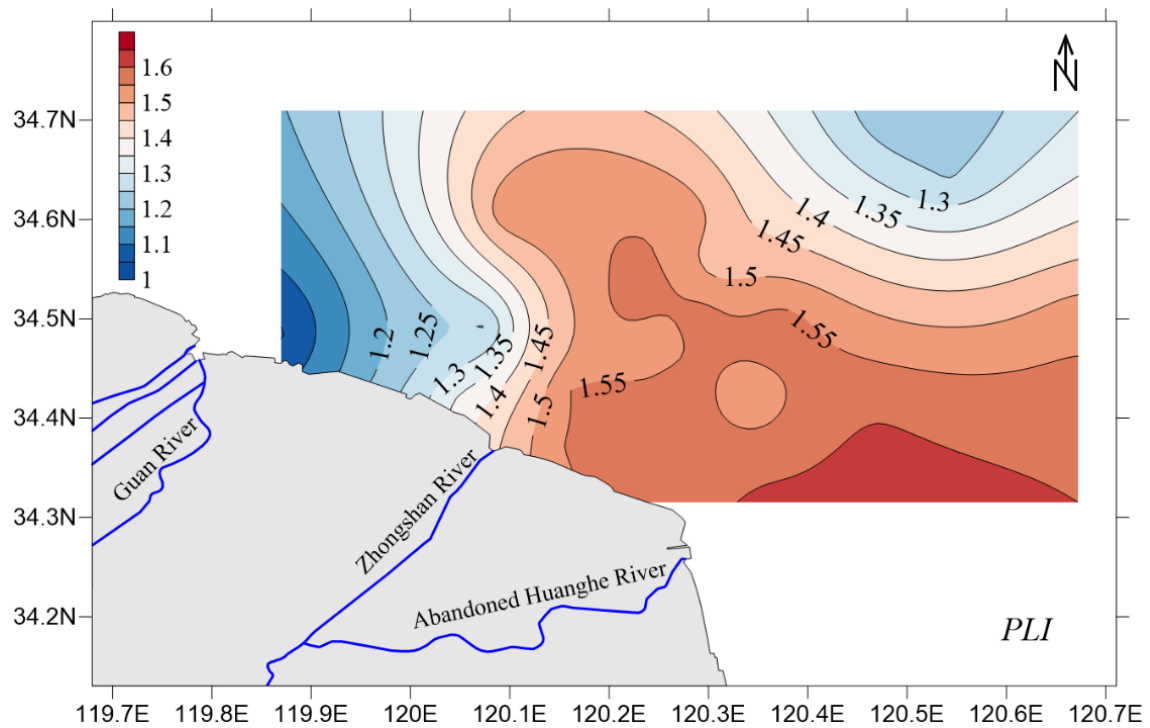

Figure 3. The distribution of the pollution load index (PLI) of heavy metals in surface sediments 


\section{Potential ecological risk assessment}

Table 5 shows the potential ecological risk index of each heavy metal (Eq. 4) and their composite potential ecological risk index (Eq. 5). Figure 4 shows the distribution of composite ecological risk indices. In May 2018, the ranges of ecological risk indices of the tested heavy metals are as follows. For $\mathrm{Hg}$, the index fluctuates between 11.18 and 49.91 with the mean standing at 30.80; for As, the index fluctuates between 7.75 and 24.53 with the mean standing at 17.12 ; for $\mathrm{Cu}$, the index fluctuates between 5.96 and 9.22 with the mean standing at 7.42 ; for $\mathrm{Pb}$, the index fluctuates between 7.63 and 11.32, with the mean standing at 9.55; for $\mathrm{Zn}$, the index fluctuates between 1.28 and 1.70, with the mean standing at 1.50; for $\mathrm{Cd}$, the index fluctuates between 97.86 and 188.57, with the mean standing at 128.82; and for $\mathrm{Cr}$, the index fluctuates between 1.19 and 1.89, with the mean standing at 1.36. In terms of the average potential ecological risk index, the seven heavy metals are ranked as $\mathrm{Cd}>\mathrm{Hg}>\mathrm{As}>\mathrm{Pb}>\mathrm{Cu}>\mathrm{Zn}>\mathrm{Cr}$. According the grading standard of Potential ecological risk index shown in Table 1, Cd is marked as at the level of medium high and high ecological risk; $\mathrm{Hg}$ is marked as at the level of low and a medium ecological risk; and other heavy metals are marked as at the level of low ecological risks. The composite potential ecological risk index of the study area is between 146.68 and 247.33 (average of 196.57); hence, the study area is under medium-high ecological risks with $\mathrm{Cd}$ and $\mathrm{Hg}$ being the major contributors.

The composite potential ecological risk index increases from the Guan River estuary to the abandoned Yellow River estuary, with the waters near the latter estuary showing the highest indices. This distribution is similar to the distribution of the heavy metal pollution load index.

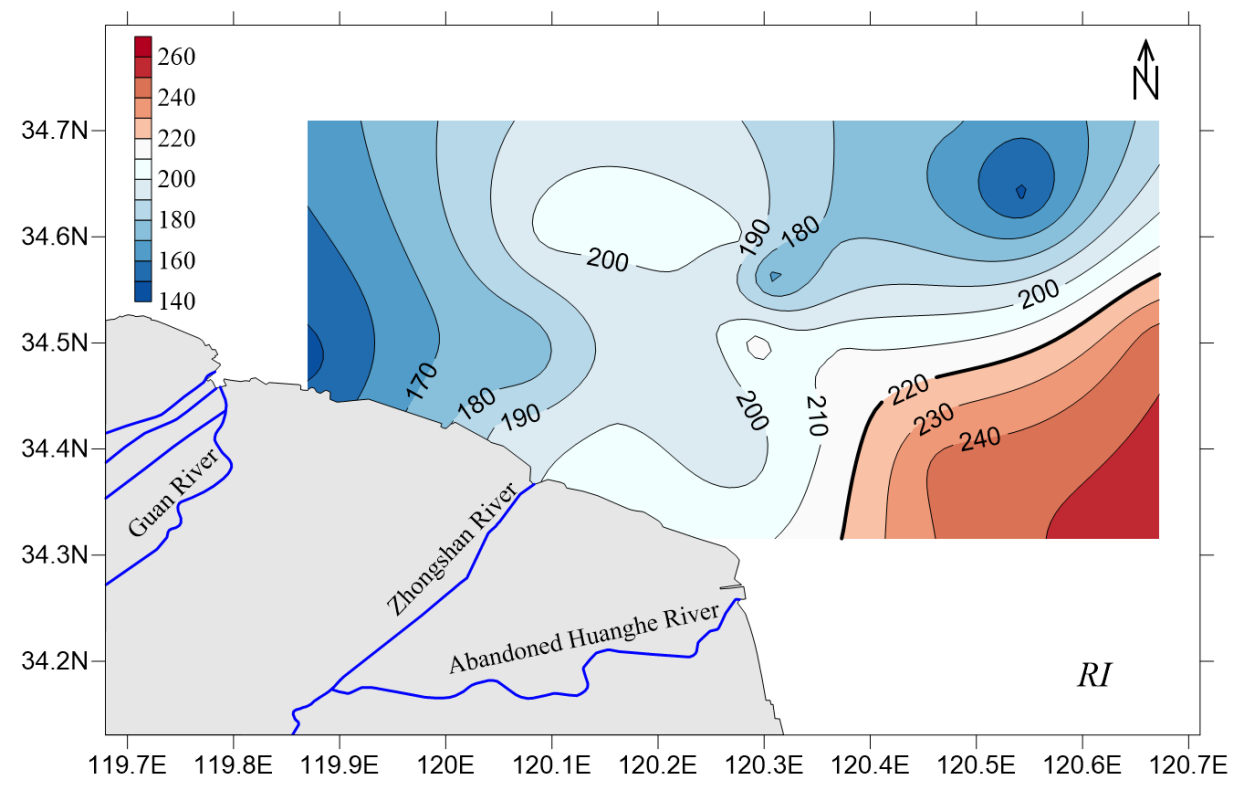

Figure 4. The distribution of the comprehensive ecological risk index

\section{Source of heavy metal}

\section{Analysis of heavy metals in surface sediments}

Correlation among heavy metals reflects the correlation among different elements, which will help recognize the sources of heavy metals (Lv et al., 2015). Table 6 shows 
the Pearson correlation coefficients between each pair of heavy metals. $\mathrm{Hg}$ and As (the Pearson coefficient is 0.694), as well as $\mathrm{Zn}$ and $\mathrm{Cu}$ (the Pearson coefficient of which is 0.681 ) are positively correlated, which indicates the correlation between $\mathrm{Hg}$ and As and that between $\mathrm{Zn}$ and $\mathrm{Cu}$ is strong and that elements in each pair are highly homogenous.

Table 6. Correlation coefficient of heavy metal elements

\begin{tabular}{c|c|c|c|c|c|c|c}
\hline & $\mathbf{H g}$ & $\mathbf{A s}$ & $\mathbf{C u}$ & $\mathbf{P b}$ & $\mathbf{Z n}$ & $\mathbf{C d}$ & $\mathbf{C r}$ \\
\hline $\mathbf{H g}$ & 1 & & & & & & \\
$\mathbf{A s}$ & $0.694^{* *}$ & 1 & & & & & \\
$\mathbf{C u}$ & -0.080 & 0.000 & 1 & & & & \\
$\mathbf{P b}$ & 0.133 & 0.263 & 0.201 & 1 & & & \\
$\mathbf{Z n}$ & 0.170 & 0.244 & $0.681^{* *}$ & 0.055 & 1 & & \\
$\mathbf{C d}$ & 0.104 & -0.122 & 0.439 & 0.038 & $0.531^{*}$ & 1 & \\
$\mathbf{C r}$ & 0.145 & -0.079 & 0.001 & -0.308 & 0.166 & 0.197 & 1 \\
\hline
\end{tabular}

**Significant correlation at 0.01 level (bilateral). *Significant correlation at 0.05 level (bilateral)

\section{Clustering analysis of heavy metals in surface sediments}

We performed clustering analysis using SPSS for the seven heavy metals and obtained data from 20 sampling sites, and the analysis of the results is shown in Figure 5. The results show that the heavy metals can be divided into three categories. The first category includes $\mathrm{Cu}, \mathrm{Zn}$, and $\mathrm{Pb}$; the second category includes $\mathrm{Cd}$ and $\mathrm{Cr}$; and the third category includes $\mathrm{Hg}$ and $\mathrm{As}$. $\mathrm{Hg}$ and $\mathrm{As}$ and $\mathrm{Cu}$ and $\mathrm{Zn}$ fall into the same category, which is consistent with the correlation analysis result. This indicates a high degree of homology between $\mathrm{Hg}$ and $\mathrm{As}$ and between $\mathrm{Cu}$ and $\mathrm{Zn}$.

The 20 monitoring stations can be divided into two clusters. Stations 1, 4, 6, 7, 12 , $14,15,17,19$, and 20 are located in waters near the shore from the Zhongshan River estuary to the port are part of the first cluster. Stations 2, 3, 5, 8, 9, and 18 are located in the coastal waters from the Guan River estuary to the Zhongshan River estuary, as well as in the distant waters from the shore are part of the second cluster.

\section{Analysis of source of heavy metals in surface sediments}

The results from Pearson correlation coefficient and the cluster analysis show a high level of homology between $\mathrm{Zn}$ and $\mathrm{Cu}$. Given the distribution of heavy metal concentration, the distribution of $\mathrm{Zn}$ and that of $\mathrm{Cu}$ is very similar because the high concentration area of both metals occurs at the waters near the Zhongshan River estuary. Therefore, the concentration of $\mathrm{Zn}$ and $\mathrm{Cu}$ may be subject to the influence of land-sourced pollutants discharged into the sea from Zhongshan River and from outfalls of the chemical industrial parks near the Zhongshan River estuary. The highest concentration of $\mathrm{Zn}$ is observed near the wind-power stations; therefore, the windpower stations along both sides of the Zhongshan River estuary may be contributors to the increase in the concentration of $\mathrm{Zn}$. The sacrificial anode anticorrosion method used by marine wind power stations releases $\mathrm{Zn}$, which will eventually increase the concentration of $\mathrm{Zn}$ in sediments.

$\mathrm{Zn}, \mathrm{Cu}$, and $\mathrm{Pb}$ are chalcophiles and they share similar geochemical processes in terms of the source, transportation, and concentration. Clustering analysis shows that $\mathrm{Pb}$ 
can be classified into the same category as $\mathrm{Zn}$ and $\mathrm{Cu}$. However, the distribution diagram and the Pearson coefficients indicate that $\mathrm{Pb}$ differs from these other two metals in terms of the source. A high concentration of $\mathrm{Pb}$ is observed near the Guan River port and outer waters of the port, which indicates that port development is the major contributor to the increasing concentration of $\mathrm{Pb}$. $\mathrm{Pb}$ gets concentrated in the waters of the port, and related studies have confirmed that engine oil containing $\mathrm{Pb}$ increases the concentration of $\mathrm{Pb}$ (Blake and Goulding, 2002; Wilcke et al., 1998; Lv et al., 2015). As the port sees a lot of traffic of ships and vessels, the constant combustion of engine oil is very likely to cause $\mathrm{Pb}$ pollution.
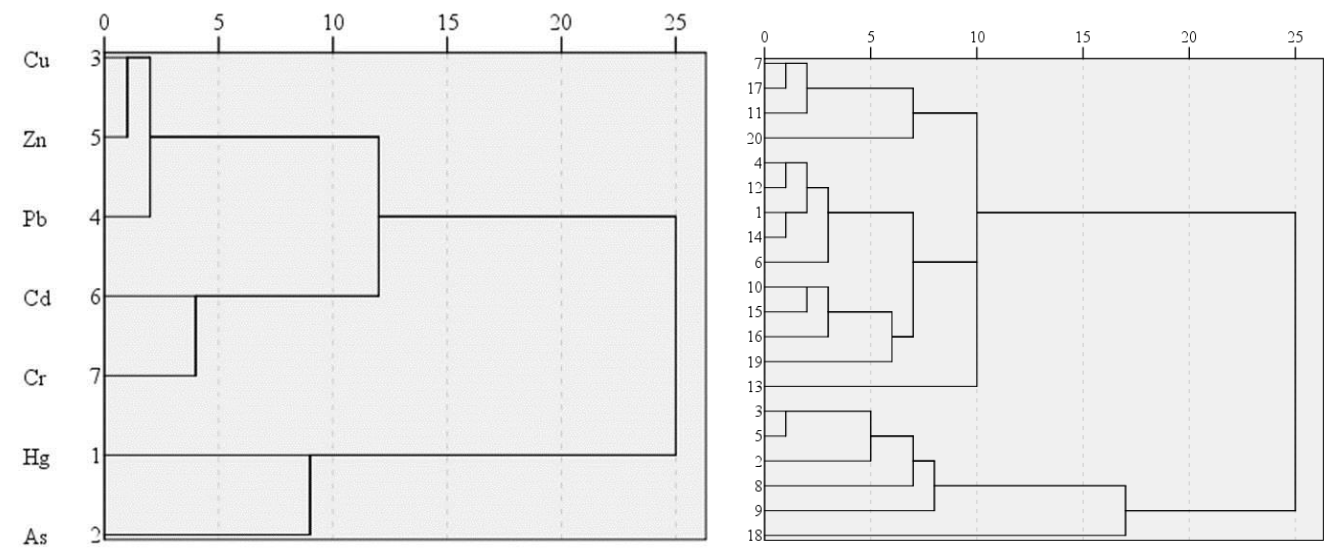

Figure 5. Heavy metal contents and sample sites location cluster analysis results

$\mathrm{Hg}$ and As share similar distribution characteristics with a high concentration of both metals being observed at the Zhongshan River estuary, the coastal port, and the outer waters of the abandoned Yellow River estuary. In general, $\mathrm{Hg}$ and As are obtained from human activities (Liu et al., 2003; Lv et al., 2013); therefore, their concentration is influenced by the discharge of pollutants from rivers, the outfalls of industrial parks, and port development activities.

Based on clustering analysis, we can group $\mathrm{Cd}$ and $\mathrm{Cr}$ into the same cluster; however, this categorization differs from the correlation analysis results. The Pearson correlation coefficient between $\mathrm{Cd}$ and $\mathrm{Cr}$ is not high, which indicates that these two metals have no obvious correlation. The concentration of $\mathrm{Cr}$ is below the background value and is primarily derived from nature; however, the concentration of $\mathrm{Cd}$ is higher than the background value and is primarily derived from human activities. These two metals share similar spatial distribution features as their concentration increases from the Guan River estuary to the Abandoned Yellow River estuary, and then from the shore to the sea. This distribution is consistent with the grain size of surface sediments in the study area. However, it differs in terms of the high-concentration area: the high concentration of $\mathrm{Cd}$ occurs in then outer waters from the Zhongshan River estuary to the abandoned Yellow River estuary, particularly in the waters around the abandoned Yellow River estuary. Cd is a standard element in chemical fertilizers (Lv et al., 2015), and the abandoned Yellow River is banked by crop fields; therefore, the high concentration of $\mathrm{Cd}$ in the outer waters, a bit far away from the abandoned Yellow River estuary, is possibly caused by the agricultural wastewater discharged from crop fields into the river. However, the high concentration of $\mathrm{Cd}$ is not seen in the estuary of the abandoned Yellow River estuary, but in the outer waters far away from the estuary 
because the abandoned Yellow River estuary is highly corrosive. Moreover, in the waters with an isobath of $-5 \mathrm{~m}$, the shallow waves corrode the seabed, which takes away the fine particles and leaves large-size particles behind; therefore, the surface sediments are large in grain size $(\mathrm{Hu}, 2014)$. Note that sediments outside the abandoned Yellow River estuary are large in grain size, which makes it difficult for heavy metals to attach; therefore, there is a high concentration of $\mathrm{Cd}$ in the outer waters that are far away from the estuary.

Clustering analysis of the monitoring stations indicates that the distribution of heavy metals is subject to the joint impact of human activities and natural factors. The sources of heavy metals in surface sediments near the shore from the Zhongshan River estuary to the abandoned Yellow River estuary are identical such as pollutants discharged into the sea from rivers, sewage outfalls, and ports and wind-power stations. In the study area, the grain size of sediments is small, which makes it very easy for heavy metals to attach themselves; therefore, the concentration of heavy metals is high. The coastal waters from the Guan River estuary to the Zhongshan River estuary suffer from lesser heavy metal pollution because there are fewer development activities in this area. Moreover, there is a $10-\mathrm{km}$-long seawall on both sides of Guan River, which directs pollutants from the river to the sea and hence reduces the pollution in waters near the shore. Furthermore, the coastal areas from the Guan River estuary to the Zhongshan River estuary have the largest grain sizes of surface sediments in the study area, so the concentration of heavy metals in this area is low, and the outer waters away from the shore in this area have low concentration of heavy metals because human activities are lesser.

Based on one-tine heavy metal contents in sediments of the Abandoned Yellow River Delta, this study analyzed the status, distribution characteristics and ecological risk of heavy metal pollution, and speculated the sources of pollution. For long-term heavy metal contents changes, distribution rules and characteristics, continuous monitoring and further analysis of the water quality are still needed in the abandoned Yellow River Delta. In the follow-up study, on basis of long-term and multiple monitoring, it is necessary to analyze the risk of heavy metal content and the correlation between water, sediment and organism. In the future, it is necessary to strengthen the accurate study of the sources of heavy metals by more means and methods.

\section{Conclusion}

Based on the results, the following conclusions can be drawn.

The average concentration of $\mathrm{Hg}, \mathrm{As}, \mathrm{Cu}, \mathrm{Pb}, \mathrm{Zn}, \mathrm{Cd}$, and $\mathrm{Cr}$ in the surface sediments in the northern waters of the abandoned Yellow River delta in May 2018 is $0.0177,12.635,22.28,21.77,70.89,0.18$, and $40.86 \mathrm{mg} / \mathrm{kg}$. Among these metals, the average concentration of $\mathrm{As}, \mathrm{Cu}, \mathrm{Pb}, \mathrm{Zn}$, and $\mathrm{Cd}$ exceeds the background value of tidal marshes in Jiangsu by a factor of $1.71,1.48,1.91,1.50$, and 4.29 , respectively.

In terms of spatial distribution, the heavy metal concentration in the study area increases from the Guan River estuary to the abandoned Yellow River estuary, and then from the shore to the sea. Such a distribution pattern is consistent with that of the grain size of sediments in the study area. Except $\mathrm{Cr}$, all other heavy metals show the highest concentration at either the estuaries or the port.

The heavy metal pollution load index of surface sediments in the study area fluctuates within between 1.04 and 1.61 (average of 1.47), and the study area is marked 
as medium-level pollution. The index increases from the Guan River estuary to the abandoned Yellow River estuary, with the outer waters from the Zhongshan River estuary to the abandoned Yellow River estuary marking the highest indices. The analysis of the geo-accumulation index shows that $\mathrm{Cd}$ has the highest geo-accumulation index and is rated as mild-medium pollution to medium pollution; $\mathrm{Pb}$ is rated as mild pollution; $\mathrm{As}, \mathrm{Cu}$, and $\mathrm{Zn}$ are rated as clean or mild pollution; and $\mathrm{Hg}$ and $\mathrm{Cr}$ are rated as clean.

The analysis of the single-factor potential ecological risk index shows that $\mathrm{Cd}$ is at the level of medium-high and high ecological risks, $\mathrm{Hg}$ is at the level of low-medium ecological risks, and other heavy metals are at the level of low ecological risks. The composite ecological risk index shows that the study area is at the level of medium-high ecological risks with $\mathrm{Cd}$ and $\mathrm{Hg}$ being the primary contributors to ecological risks. The composite ecological risk index increases from the Guan River estuary to the Abandoned Yellow River estuary, and the outer waters of the Abandoned Yellow River estuary marks the largest indices. Waters from the Zhongshan River estuary to the abandoned Yellow River estuary are most susceptible to heavy metal ecological risks.

The distribution of heavy metal concentration in the study area is influenced by both human and natural factors. The concentration of $\mathrm{Cr}$ is lower than the background value and is mainly derived from natural sources, while other heavy metals are mainly derived from human activities. Heavy metals in surface sediments in the near-shore waters from the Zhongshan River estuary to the abandoned Yellow River estuary share the same sources such as pollutants discharged into the sea from rivers, sewage outfalls, and ports and wind-power stations. The grain size of sediments in this area is small, which makes it easy for heavy metals to attach themselves, so the concentration of heavy metals in this area is high. The near-shore waters from the Guan River estuary to the Zhongshan River estuary suffer from lesser heavy metal pollution because there are fewer development activities and the grain size of sediments in this area is large. Consequently, the concentration of heavy metals in this area is low, and the concentration of heavy metals in the outer waters of the study area is also relatively low because of fewer human activities.

\section{REFERENCES}

[1] Begy, R. C., Preoteasa, L., Timar, G. A., Mihaiescu, R., Tanaselia, C., Kelemen, S., Simon, H. (2016): Sediment dynamics and heavy metal pollution history of the cruhlig lake (Danube delta, Romania). - J. Environ. Radioact. 153: 167-175.

[2] Blake, L., Goulding, K. W. T. (2002): Effects of atmospheric deposition, soil pH and acidification on heavy metal contents in soils and vegetation of semi-natural ecosystems at Rothamsted Experimental Station, UK. - Plant and Soil 240(2): 235-251.

[3] Chen, B. B., Hu, R. Q., Chen, M. D. (1985): Natural background values of environmental elements in coastal soil in Jiangsu. - Journal of Nanjing Agricultural University 8(3): 5460.

[4] Chen, H. Q., Peng, J., Chen, S. L., et al. (2014): Spatial variability characteristics of sediment grain size in sea area of the abandon Yellow River Delta, north of Jiangsu Province. - Journal of Applied Oceanography 33(4): 574-580.

[5] Guan, Q., Wang, L., Pan, B., et al. (2016): Distribution features and controls of heavy metals in surface sediments from the riverbed of the Ningxia-Inner Mongolian reaches, Yellow River, China. - Chemosphere 144: 29-42. 
[6] Hakanson, L. (1980): An ecological risk index for aquatic pollution control. A sedimentological approach. - Water Research 14(8): 975-1001.

[7] Harikrishnan, N., Ravisankar, R., Chandrasekaran, A., et al. (2017): Assessment of heavy metal contamination in marine sediments of East Coast of Tamil Nadu affected by different pollution sources. - Marine Pollution Bulletin 121: 418-424.

[8] Hu, J. (2014): East China Normal University coastal evolution process and nearshore suspended sediment research of the abandoned Yellow River Delta. - Thesis for Master's degree in 2014, East China Normal University.

[9] Jahan, S., Strezov, V. (2018): Comparison of pollution indices for the assessment of heavy metals in the sediments of seaports of NSW, Australia. - Marine Pollution Bulletin 128: 295-306.

[10] Keshavarzi, B., Hassanaghaei, M., Moore, F., et al. (2018): Heavy metal contamination and health risk assessment in three commercial fish species in the Persian Gulf. - Marine Pollution Bulletin 129(1): 245-252.

[11] Li, C., Song, C., Yin, Y., et al. (2015): Spatial distribution and risk assessment of heavy metals in sediments of Shuangtaizi estuary, China. - Marine Pollution Bulletin 98(1): 358-364.

[12] Li, F., Xu, M. (2014): Source characteristics and contamination evaluation of heavy metals in the surface sediments of Haizhou Bay. - Environmental Science 35(3): 10351040.

[13] Li, G. H., Cao, Z. M., Lan, D. Z., Xu, J., Wang, S. S., Yin, W. H. (2007): Spatial variations in grain size distribution and selected metal contents in the Xiamen Bay, China. - Environ. Geol. 52: 1559-1567.

[14] Liang, X., Song, J., Duan, L., et al. (2018): Source identification and risk assessment based on fractionation of heavy metals in surface sediments of Jiaozhou Bay, China. Marine Pollution Bulletin 128: 548-556.

[15] Liu, R. H., Wang, Q. C., Lu, X. G., et al. (2003): Distribution and speciation of mercury in the peat bog of Xiaoxing'an Mountain, northeastern China. - Environmental Pollution 124(1): 39-46.

[16] Lv, J., Liu, Y., Zhang, Z., et al. (2015): Identifying the origins and spatial distributions of heavy metals in soils of Ju country (Eastern China) using multivariate and geostatistical approach. - Journal of Soils and Sediments 15(1): 163-178.

[17] Lv, J. S., Liu, Y., Zhang, Z. L., et al. (2013): Factorial kriging and stepwise regression approach to identify environmental factors influencing spatial multi-scale variability of heavy metals in soils. - Journal of Hazardous Materials 261: 387-397.

[18] Monferran, M. V., Garnero, P. L., Wunderlin, D. A., de los Angeles Bistoni, M. (2016): Potential human health risks from metals and as via Odontesthes bonariensis consumption and ecological risk assessments in a eutrophic lake. - Ecotoxicol. Environ. Saf. 129: 302-310.

[19] Müller, G. (1969): Index of geoaccumulation in sediments of the Rhine River. Geojournal 2(3): 108-118.

[20] Nguyen, T. T. H., Zhang, W., Li, Z., et al. (2016): Assessment of heavy metal pollution in Red River surface sediments, Vietnam. - Marine Pollution Bulletin 113(1-2): 513.

[21] Phillips, D. P., Human, L. R., Adams, J. B., et al. (2015): Wetland plants as indicators of heavy metal contamination. - Marine Pollution Bulletin 92(1): 227-232.

[22] Reddy, B. C., Jayaraju, N., Sreenivasulu, G., et al. (2016): Heavy metal pollution monitoring with foraminifera in the estuaries of Nellore coast, East coast of India. Marine Pollution Bulletin 113(1): 542-551.

[23] Singh, K. P., Mohan, D., Singh, V. K., et al. (2005): Studies on distribution and fractionation of heavy metals in Gomti river sediments - a tributary of the Ganges, India. - Journal of Hydrology 312(1): 14-27. 
[24] Sun, C. Y., Liu, J. S., Wang, Y., et al. (2013): Multivariate and geostatistical analyses of the spatial distribution and sources of heavy metals in agricultural soil in Dehui, Northeast China. - Chemosphere 92(5): 517-523.

[25] Tomlinson, D. L., Wilson, J. G., Harris, C. R., Jeffery, D. W. (1980): Problems in the assessment of heavy-metal levels in estuaries and the formation of a pollution index. Helgoländer Meeresuntersuchungen 33: 566-575.

[26] Wang, M., Tong, Y., Chen, C., et al. (2018): Ecological risk assessment to marine organisms induced by heavy metals in China's coastal waters. - Marine Pollution Bulletin 126: 349-356.

[27] Wang, Y. S., Lou, Z. P., Sun, C. C., Sun, S. (2008): Ecological environment changes in Daya Bay, China, from 1982 to 2004. - Marine Pollution Bulletin 56: 1871-1879.

[28] Wilcke, W., Muller, S., Kanchanakool, N., et al. (1998): Urban soil contamination in Bangkok: heavy metal and aluminium partitioning in topsoils. - Geoderma 86(3): 211228.

[29] Wu, G., Shang, J., Pan, L., Wang, Z. (2014): Heavy metals in surface sediments from nine estuaries along the coast of Bohai bay, northern China. - Marine Pollution Bulletin 82(1-2): 194-200.

[30] Zhang, J. P., Jiao, X. M., Fang, N., J., et al. (2017): Sources and risk assessment of heavy metals in sediments in Jiangsu coastal areas. - China Environmental Science 37(4): 15141522 .

[31] Zhang, L. (2015): The coastal erosion-deposition evolution and controlling factors of the abandoned Yellow River delta in northern Jiangsu province. - Doctoral Dissertation in 2016, East China Normal University.

[32] Zhang, M., Bao, Z. Y., Chen, G. G., Yong, T. J., et al. (2017): Characteristics and risks of heavy metals content in surface sediment of tidal flat areas in eastern China. Environmental Science 38(11): 4513-4524.

[33] Zhang, P., Hu, R., Zhu, L., et al. (2017): Distributions and contamination assessment of heavy metals in the surface sediments of western Laizhou Bay: implications for the sources and influencing factors. - Marine Pollution Bulletin 119(1): 429-438.

[34] Zhao, G., Lu, Q., Ye, S., Yuan, H., Ding, X., Wang, J. (2016): Assessment of heavy metal contamination in surface sediments of the west Guangdong coastal region, China. Marine Pollution Bulletin 108(1-2): 268-274.

[35] Zhao, Y. F., Xu, M., Liu, Q., et al. (2018): Study of heavy metal pollution, ecological risk and source apportionment in the surface water and sediments of the Jiangsu coastal region, China: A case study of the Sheyang Estuary. - Marine Pollution Bulletin 137: 601-609.

[36] Zhu, Z. M., Li, Z. G., Bi, X. Y., Han, Z. X., Yu, G. H. (2013): Response of magnetic properties to heavy metal pollution in dust from three industrial cities in China. Hazardous Materials 246-247: 189-198. 